\title{
Parâmetros hematológicos e bioquímicos de ovinos da raça Dorper
}

\section{Hematological and biochemical parameters of Dorper ewes}

\author{
Karina Medici Madureira ${ }^{1 *}$; Viviani Gomes ${ }^{2}$; Brenda Barcelos ${ }^{3}$; Breno Henrique \\ Zani ${ }^{4}$; Carolina de Lara Shecaira ${ }^{5}$; Camila Costa Baccili ${ }^{5}$; Fernando José Benesi ${ }^{2}$
}

\section{Resumo}

\begin{abstract}
A fim de estabelecer os valores hematológicos e bioquímicos de ovinos da raça Dorper e avaliar a influência do sexo e idade nestas determinações, 72 animais foram distribuídos em três grupos experimentais de acordo com a faixa etária, sendo o Grupo 1 (G1) composto por animais com até 12 meses de idade ( $n=28)$, o Grupo 2 (G2) composto por animais de 13 a 36 meses de idade ( $n=37)$ e o Grupo 3 (G3) por animais de 37 a 60 meses de idade $(n=7)$. Os animais foram distribuídos ainda em outros dois grupos exprimentais, de acordo com o sexo, sendo o Grupo 4 (G4) composto por fêmeas (n=57) e o grupo 5 (G5) por machos ( $\mathrm{n}=15)$. Avaliando-se os resultados obtidos para os exames hematológicos e bioquímicos verificou-se que os valores médios de hemácias $\left(13,4 \pm 2,5 \times 10^{6} / \mu \mathrm{L}\right)$, hemoglobina $(12,6$ $\pm 1,3 \mathrm{~g} / \mathrm{dL})$, volume globular $(37,5 \pm 3,7 \%)$, leucócitos totais $(7.116,0 \pm 1.967,0 / \mu \mathrm{L})$ e neutrófilos segmentados $(4.168,0 \pm 1.501,0 / \mu \mathrm{L})$ foram maiores nos animais do $\mathrm{G} 1$, assim como a ureia, GGT e FA $(52,0 \pm 17,0 \mathrm{mg} / \mathrm{dL}, 93,0 \pm 19,0 \mathrm{UI} / \mathrm{L}$ e 257,0 \pm 125,0 UI / L, respectivamente). Comparando-se os sexos, verificou-se que os valores de leucócitos totais $(7.576,0 \pm 2.082,0 / \mu \mathrm{L})$, neutrófilos segmentados $(4.296,0 \pm 1.510,0 / \mu \mathrm{L})$ e linfócitos $(2.428,0 \pm 1.084,0 / \mu \mathrm{L})$ foram maiores nos machos $(\mathrm{G} 5)$. Os valores de creatinina $(1,3 \pm 0,4 \mathrm{mg} / \mathrm{dL})$, proteínas totais séricas $(6,3 \pm 0,9 \mathrm{~g} / \mathrm{dL})$ e globulinas $(3,7 \pm 1,0 \mathrm{~g} / \mathrm{dL})$ foram maiores nas fêmeas (G4). A análise estatística dos resultados encontrados permitiu determinar os valores de referência para os constituintes hematológicos e bioquímicos de ovinos da raça Dorper, além de concluir que ocorreram variações nos referidos parâmetros, influenciados pelo sexo e por diferentes faixas etárias.
\end{abstract}

Palavras-chave: Hematologia, bioquímica, ovinos

\begin{abstract}
In order to establish hematological and biochemical Dorper sheep values and evaluate the influence of sex and age in these determinations, 72 animals were assigned to three experimental groups according to age: Group 1 (G1) consisting of animals up to 12 months of age (n=28), Group 2 (G2) composed of animals from 13 to 36 months ( $n=37$ ) and Group 3 (G3) for animals from 37 to 60 months (n=7). The animals were still divided in another two groups according to gender: Group 4 (G4) - females $(\mathrm{n}=57)$ and Group 5 (G5) - males ( $\mathrm{n}=15$ ). Evaluating the results obtained for hematological and biochemical examinations it was found that the mean values of $\mathrm{RBC}\left(13.4 \pm 2.5 \times 10^{6} / \mu \mathrm{L}\right)$, hemoglobin $(12.6 \pm$ $1.3 \mathrm{~g} / \mathrm{dL})$, packed cell volume $(37.5 \pm 3.7 \%)$, total leukocytes $(7116.0 \pm 1967.0 / \mu \mathrm{L})$ and segmented neutrophils $(4168.0 \pm 1501.0 / \mu \mathrm{L})$ were higher in the animals of G1, as well as urea, GGT and ALP
\end{abstract}

\footnotetext{
${ }^{1}$ Prof $^{a}$ do Dept ${ }^{\mathrm{o}}$ de Anatomia, Patologia e Clínicas Veterinárias, Escola de Medicina Veterinária e Zootecnia, Universidade Federal da Bahia, UFBA, Bahia, BA. E-mail: karinamedici@yahoo.com.br

${ }^{2}$ Profs. do Dept ${ }^{\mathrm{o}}$ de Clínica Médica, Faculdade de Medicina Veterinária e Zootecnia, Universidade de São Paulo, USP, São Paulo, SP. E-mail: viviani.gomes@usp.br; febencli@usp.br

${ }^{3}$ Pós-graduanda da Faculdade de Zootecnia e Engenharia de Alimentos, USP, São Paulo, SP. E-mail: brendabarcelos@yahoo.com.br

${ }^{4}$ Discente do Curso de Medicina Veterinária, Centro Universitário Anhanguera, Campus Leme. E-mail: brenozani@hotmail.com

${ }^{5}$ Pós-graduanda(s) do Dept ${ }^{\circ}$ de Clínica Médica, Faculdade de Medicina Veterinária e Zootecnia, USP, São Paulo, SP. E-mail: carol_1shecaira@hotmail.com; camila_ramosc@hotmail.com

* Autor para correspondência
} 
$(52.0 \pm 17.0 \mathrm{mg} / \mathrm{dL}, 93.0 \pm 19.0 \mathrm{IU} / \mathrm{L}, 257.0 \pm 125.0 \mathrm{IU} / \mathrm{L}$, respectively). Comparing the gender, it was found that the values of total leukocytes $(7576.0 \pm 2082.0 / \mu \mathrm{L})$, segmented neutrophils $(4296.0 \pm$ $1510.0 / \mu \mathrm{L})$ and lymphocytes $(2428.0 \pm 1084.0 / \mu \mathrm{L})$ were greater in males $(\mathrm{G} 5)$. The values of creatinine $(1.3 \pm 0.4 \mathrm{mg} / \mathrm{dL})$, serum total protein $(6.3 \pm 0.9 \mathrm{~g} / \mathrm{dL})$ and globulins $(3.7 \pm 1.0 \mathrm{~g} / \mathrm{dL})$ were higher in females (G4). Statistical analysis of the results allowed to determine reference values for hematological and biochemical constituents of Dorper sheep breed, and concluded that there were variations in these parameters influenced by gender and different age groups.

Key words: Hematology, biochemistry, sheep

Os ovinos da raça Dorper surgiram em 1930 na África do Sul, do cruzamento das raças Dorset Horn e Cabeça Negra da Pérsia. Tem por suas características a rusticidade, alta adaptabilidade a temperaturas adversas, ótimo acabamento de carcaça e alta prolificidade (SOUSA; LEITE, 2000). Em função destas características, a raça foi introduzida no Brasil em 1998 (CARVALHO; OLIVEIRA; DOMINGUES, 2001) e sua criação encontra-se em ascensão contínua até os dias atuais.

Os valores hematológicos e bioquímicos da espécie ovina foram inicialmente relatados por Schalm (1961), sendo amplamente utilizados como valores de referência para tal espécie. No entanto, animais de diferentes raças, idades, sexo e local de criação possuem necessidades nutricionais, energéticas e metabólicas diversas, que são refletidas nos seus perfis hematológicos e bioquímicos. Além disso, as enfermidades que podem acometer os animais da espécie ovina ocasionam, na maioria das vezes, em alterações hematológicas e bioquímicas, sendo de fundamental importância a correta identificação destas alterações, embasada nos valores de referência determinados para a espécie em questão, tornando os exames laboratoriais auxiliares no diagnóstico das doenças e prevenção de prejuízos econômicos que estas podem causar.

$\mathrm{Na}$ bibliografia brasileira e internacional consultada (RAMOS et al., 1994; BATISTA et al., 2009, MEIRA JUNIOR et al., 2009; SANTANA et al., 2009), verificou-se que existem trabalhos relacionados aos parâmetros hematológicos e bioquímicos de ovinos, porém, em nenhum destes a hematologia e a bioquímica clínica de ovinos da raça Dorper foi estudada.
Em virtude dos diversos fatores relacionados à influência nos perfis hematológicos e bioquímicos, assim como a ausência de relatos que determinam os valores de referência para a raça Dorper, surge a necessidade de se determinar tais perfis, além da importância que estes possuem no auxílio do diagnóstico e prognóstico das afecções que acometem os ovinos. Sendo assim, o objetivo deste trabalho foi estabelecer os valores hematológicos e bioquímicos de referência e avaliar a influência dos fatores etários e sexuais nestes parâmetros, em ovinos da raça Dorper.

Foram utilizados 72 ovinos hígidos da raça Dorper, sendo 57 fêmeas e 15 machos, criados em quatro propriedades do interior do estado de São Paulo. O estado de higidez dos animais foi avaliado segundo Dirksen, Gründer e Stöber (1993), sendo utilizado como método de exclusão amostral. Os animais selecionados foram distribuídos em cinco grupos experimentais, sendo que em três destes grupos os animais foram distribuídos segundo a faixa etária, pertencendo ao Grupo 1 (G1) animais com idade inferior ou igual a 12 meses $(\mathrm{n}=28)$; o Grupo 2 (G2) foi composto por 37 animais entre 13 a 36 meses; e o Grupo 3 (G3) composto por sete animais entre 37 a 60 meses. Nos dois grupos restantes, os animais foram distribuídos de acordo com o sexo, sendo o Grupo 4 (G4) formado por fêmeas $(n=57)$ e o Grupo 5 (G5), por machos ( $\mathrm{n}=15)$.

As amostras de sangue foram obtidas por meio da venopunção da jugular externa, por sistema a vácuo, e armazenadas em dois frascos, um contendo o anticoagulante etileno diaminotetracetato de sódio (EDTA) a 10\%, e outro isento de anticoagulante, para a realização do hemograma e provas bioquímicas, respectivamente. 
Com relação aos valores hematológicos, foram determinados o volume globular (VG), a quantidade de hemoglobina $(\mathrm{Hb})$, a contagem de hemácias $(\mathrm{He})$, os índices hematimétricos Volume Corpuscular Médio (VCM), Hemoglobina Corpuscular Média (HCM) e Concentração Hemoglobínica Corpuscular Média (CHCM), assim como a contagem total e diferencial dos leucócitos.

Para a determinação do volume globular (VG), capilares de vidro foram preenchidos com sangue, devidamente vedados e centrifugados a 15.000 rpm, durante 5 minutos. Após a centrifugação dos capilares, a coluna formada pelas hemácias foi interpretada em cartão de leitura apropriado, e o valor determinado em porcentagem (BIRGEL, 1982).

A determinação do valor da hemoglobina sanguínea foi realizada através da diluição da amostra de sangue total, na proporção de 1:250, em líquido de Drabkin e a leitura da reação colorimétrica foi realizada em espectrofotômetro, sendo o valor da hemoglobina determinado em g/dL (BIRGEL, 1982).

Para a determinação do número total de hemácias, as amostras de sangue foram diluídas, na proporção 1:200, em pipeta hematimétrica com líquido de Gower e a contagem foi realizada em câmara hematimétrica de Neubauer modificada segundo Birgel (1982), sendo o resultado apresentado em número de hemácias/ $\mu \mathrm{L}$ de sangue.

Os índices hematimétricos Volume Corpuscular Médio (VCM), Hemoglobina Corpuscular Média (HCM) e Concentração Hemoglobínica Corpuscular Média (CHCM), foram calculados a partir dos resultados obtidos para o $\mathrm{VG}, \mathrm{Hb}$ e $\mathrm{He}$, utilizandose fórmulas matemáticas (BIRGEL, 1982).

Para a contagem total de leucócitos, cada amostra de sangue com EDTA foi diluída na proporção 1:20, em pipeta hematimétrica com líquido de Thoma, e a contagem foi realizada em câmara hematimétrica de Neubauer modificada segundo Birgel (1982), sendo o resultado apresentado em milhares de células por $\mu \mathrm{L}$ de sangue.

Os esfregaços sanguíneos realizados logo após a colheita das amostras de sangue foram corados com Rosenfeld (1947), para a avaliação diferencial dos leucócitos sanguíneos. Em cada esfregaço foram contados 100 leucócitos, utilizando-se microscopia comum e aumento de $1000 x$, identificando-se os polimorfonucleares granulócitos (neutrófilos, eosinófilos e basófilos) e os mononucleares agranulócitos (linfócitos e monócitos), segundo Birgel (1982).

As provas bioquímicas de função renal (uréia e creatinina) e atividade sérica das enzimas hepáticas (Aspartato aminotransferase - AST, Gama-glutamil transferase - GGT e Fosfatase alcalina - FA) foram realizadas por meio de um analisador bioquímico semi-automático e suas atividades quantificadas por kits comerciais (Labtest Diagnóstica $S . A ®)$ ). O valor das proteínas totais séricas (PT) foi determinado através do método do biureto, o valor sérico de albumina através do reativo de verde bromocresol e o de globulina foi obtido pela subtração dos valores individuais de proteína total e albumina, sendo os valores expressos em g/dL (HOFFMANN; SOLTER, 1997).

Os resultados obtidos foram submetidos ao teste de normalidade de Kolmogorov-Smirnov, apresentaram distribuição paramétrica e sofreram a análise de variância, com suas diferenças avaliadas pelo teste de Tukey (SAMPAIO, 1998). Os valores médios dos constituintes hematológicos e bioquímicos de ovinos da raça Dorper, avaliados conforme a faixa etária e sexo estão ilustrados nas Tabelas 1 e 2, respectivamente. 
Tabela 1. Ovinos da raça Dorper, distribuídos por faixa etária e sexo, segundo valores médios e desvios-padrão dos constituintes hematológicos.

\begin{tabular}{|c|c|c|c|c|c|}
\hline $\begin{array}{l}\text { Parâmetros/ } \\
\text { Grupos }\end{array}$ & $\begin{array}{c}\text { Grupo } 1 \\
\leq 12 \text { meses }\end{array}$ & $\begin{array}{c}\text { Grupo } 2 \\
13-36 \text { meses }\end{array}$ & $\begin{array}{c}\text { Grupo } 3 \\
37-60 \text { meses }\end{array}$ & $\begin{array}{c}\text { Grupo } 4 \\
\text { Fêmeas }\end{array}$ & $\begin{array}{l}\text { Grupo } 5 \\
\text { Machos }\end{array}$ \\
\hline $\mathrm{He}\left(\mathrm{x} 10^{6} / \mu \mathrm{L} \mathrm{sg}\right)$ & $13,4^{a} \pm 2,5$ & $12,0^{\mathrm{ab}} \pm 2,3$ & $10,2^{b} \pm 2,8$ & $12,2 \pm 2,4$ & $13,1 \pm 3,0$ \\
\hline VG (\%) & $37,5^{\mathrm{a}} \pm 3,7$ & $35,8^{\mathrm{ab}} \pm 4,0$ & $33,2^{b} \pm 5,4$ & $36,2 \pm 4,1$ & $36,3 \pm 4,5$ \\
\hline $\mathrm{Hb}(\mathrm{g} / \mathrm{dL})$ & $12,6^{a} \pm 1,3$ & $11,8^{\mathrm{ab}} \pm 1,4$ & $10,2^{b} \pm 1,6$ & $12,0 \pm 1,5$ & $12,1 \pm 1,8$ \\
\hline $\operatorname{VCM}(f l)$ & $28,7 \pm 6,3$ & $30,3 \pm 5,0$ & $33,6 \pm 7,8$ & $30,4 \pm 0,8$ & $28,3 \pm 1,1$ \\
\hline $\mathrm{HCM}(\mathrm{pg})$ & $9,6 \pm 1,6$ & $9,9 \pm 1,2$ & $10,2 \pm 1,2$ & $10,0 \pm 1,4$ & $9,3 \pm 1,0$ \\
\hline CHCM (\%) & $34,0 \pm 2,3$ & $33,2 \pm 3,0$ & $31,1 \pm 3,7$ & $33,2 \pm 3,1$ & $33,4 \pm 2,6$ \\
\hline Leuc. $(/ \mu \mathrm{L} \mathrm{sg})$ & $7.116,0^{\mathrm{a}} \pm 1.967,0$ & $6.173,0^{\mathrm{ab}} \pm 1.431,0$ & $5.007,0^{\mathrm{b}} \pm 910,0$ & $6.100,0^{b} \pm 1.673,0$ & $7.576,0^{\mathrm{a}} \pm 2.082,0$ \\
\hline Ne segm. $(/ \mu \mathrm{L} \mathrm{sg})$ & $4.168,0^{\mathrm{a}} \pm 1.501,0$ & $3.463,0^{\mathrm{ab}} \pm 1.082,0$ & $2.738,0^{b} \pm 590,0$ & $3.477,0^{\mathrm{b}} \pm 1.193,0$ & $4.296,0^{\mathrm{a}} \pm 1.510,0$ \\
\hline Ne bast. (/ $\mu \mathrm{L} \mathrm{sg})$ & $18,0 \pm 37,0$ & $8,0 \pm 22,0$ & $7,0 \pm 18,0$ & $8,0^{\mathrm{b}} \pm 22,4$ & $36,0^{\mathrm{a}} \pm 42,8$ \\
\hline Linf. ( $/ \mu \mathrm{L} \mathrm{sg})$ & $2.246,0 \pm 890,0$ & $1.953,0 \pm 868,0$ & $1.573,0 \pm 554,0$ & $1.925,0^{b} \pm 778,0$ & $2.428,0^{\mathrm{a}} \pm 1.084,0$ \\
\hline Mon. $(/ \mu \mathrm{L} \mathrm{sg})$ & $389,0 \pm 195,0$ & $684,0 \pm 1202,0$ & $406,0 \pm 218,0$ & $563,0 \pm 980,0$ & $462,0 \pm 269,0$ \\
\hline Eosin. $(/ \mu \mathrm{L} \mathrm{sg})$ & $219,0 \pm 145,0$ & $224,0 \pm 164,0$ & $274,0 \pm 330,0$ & $214,0 \pm 182,0$ & $279,0 \pm 145,0$ \\
\hline Bas. $(/ \mu \mathrm{L} \mathrm{sg})$ & $16,0 \pm 34,0$ & $21,0 \pm 42,0$ & $7,0 \pm 18,0$ & $20,0 \pm 41,0$ & $11,0 \pm 24,0$ \\
\hline
\end{tabular}

$\mathrm{a}, \mathrm{b}$ - letras minúsculas na mesma linha indicam diferenças estatísticas entre si $(\mathrm{p}<0,05)$.

$H e$ - hemácias; $V G$ - volume globular; $H b$ - hemoglobina; $V C M$ - volume corpuscular médio; $H C M$ - hemoglobina corpuscular média; $C H C M$ - concentração hemoglobínica corpuscular média; Leuc. - leucócitos totais; Ne segm. - neutrófilos segmentados; Ne bast. - neutrófilos bastonetes; Linf. - linfócitos; Mon. - monócitos; Eosin. - eosinófilos; Bas. - basófilos.

Fonte: Elaboração dos autores.

Tabela 2. Ovinos da raça Dorper, distribuídos por faixa etária e sexo, segundo valores médios e desvios-padrão dos constituintes bioquímicos sanguíneos.

\begin{tabular}{lrrrrr}
\hline \multicolumn{1}{c}{$\begin{array}{c}\text { Parâmetros } \\
\text { /Grupos }\end{array}$} & \multicolumn{1}{c}{\begin{tabular}{c} 
Grupo 1 \\
\multicolumn{1}{c}{ (12 meses }
\end{tabular}} & $\begin{array}{c}\text { Grupo 2 } \\
\mathbf{1 3 - 3 6} \text { meses }\end{array}$ & $\begin{array}{c}\text { Grupo 3 } \\
\text { 37- 60 meses }\end{array}$ & \multicolumn{1}{c}{$\begin{array}{c}\text { Grupo 4 } \\
\text { Fêmeas }\end{array}$} & \multicolumn{1}{c}{$\begin{array}{c}\text { Grupo 5 } \\
\text { Machos }\end{array}$} \\
\hline Uréia (mg/dL) & $52,0^{\mathrm{a}} \pm 17,0$ & $42,0^{\mathrm{b}} \pm 12,0$ & $43,0^{\mathrm{b}} \pm 15,0$ & $47,8 \pm 16,3$ & $40,8 \pm 10,9$ \\
Creatinina (mg/dL) & $1,2 \pm 0,3$ & $1,3 \pm 0,4$ & $1,1 \pm 0,2$ & $1,3^{\mathrm{a}} \pm 0,4$ & $1,1^{\mathrm{b}} \pm 0,2$ \\
AST (UI/L) & $138,0 \pm 71,0$ & $123,0 \pm 46,0$ & $111,0 \pm 37,0$ & $130,0 \pm 62,0$ & $123,0 \pm 28,0$ \\
GGT (UI/L) & $93,0^{\mathrm{a}} \pm 19,0$ & $78,0^{\mathrm{b}} \pm 22,0$ & $78,0^{\mathrm{b}} \pm 17,0$ & $82,0 \pm 22,0$ & $90,0 \pm 21,0$ \\
FA (UI/L) & $257,0^{\mathrm{a}} \pm 125,0$ & $154,0^{\mathrm{b}} \pm 90,0$ & $132,0^{\mathrm{b}} \pm 89,0$ & $190,0 \pm 122,0$ & $200,0 \pm 95,0$ \\
PT (g/dL) & $5,9 \pm 0,1$ & $6,3 \pm 0,1$ & $6,6 \pm 0,4$ & $6,3^{\mathrm{a}} \pm 0,9$ & $5,8^{\mathrm{b}} \pm 0,5$ \\
Albumina (g/dL) & $2,8^{\mathrm{a}} \pm 0,2$ & $2,5^{\mathrm{b}} \pm 0,4$ & $2,8^{\mathrm{a}} \pm 0,4$ & $2,6 \pm 0,4$ & $2,7 \pm 0,2$ \\
Globulinas (g/dL) & $3,1^{\mathrm{b}} \pm 0,5$ & $3,8^{\mathrm{a}} \pm 1,0$ & $3,6^{\mathrm{ab}} \pm 1,4$ & $3,7^{\mathrm{a}} \pm 1,0$ & $3,0^{\mathrm{b}} \pm 0,6$ \\
\hline
\end{tabular}

$\mathrm{a}, \mathrm{b}$ - letras minúsculas na mesma linha indicam diferenças estatísticas entre si $(\mathrm{p}<0,05)$.

$A S T$ - aspartato aminotransferase; $G G T$ - gama-glutamil transferase, $F A$ - fosfatase alcalina; $P T$ - proteínas totais séricas.

Fonte: Elaboração dos autores.

Avaliando-se os três grupos de animais separados pela faixa etária (G1, G2 e G3), pôde-se verificar que os valores do eritrograma ( $\mathrm{VG}, \mathrm{Hb}, \mathrm{He}$ ) obtidos neste trabalho foram superiores nos animais do G1 (Tabela 1), valores estes semelhantes aos obtidos por Santana et al. (2009), que avaliaram o perfil hematológico e bioquímico de machos e fêmeas da espécie ovina, sem raça definida e com idade entre
4 e 6 meses. Já os valores obtidos por Batista et al. (2009) foram inferiores aos obtidos no presente trabalho, sendo que os referidos autores avaliaram animais criados na região Nordeste do Brasil, com características climáticas e de manejo diferentes do Estado de São Paulo.

Os valores de leucócitos totais e neutrófilos segmentados também foram maiores nos animais 
do G1 (Tabela 1), concordando com os resultados obtidos por Batista et al. (2009) e Santana et al. (2009). Pôde-se observar ainda uma diminuição significativa nestes parâmetros com o avançar da idade. As oscilações leucocitárias observadas neste trabalho, para os animais do G1, podem ter sido influenciadas por diversos fatores, entre eles pelos níveis de glicocorticóides endógenos liberados de forma mais expressiva na circulação sanguínea durante as primeiras semanas de vida dos animais, em virtude do estresse sofrido no momento do nascimento e do tempo decorrido entre o nascimento e a ingestão do colostro, afetando o padrão leucocitário (BENESI, 1992).

Com relação aos valores bioquímicos, os valores médios de ureia, GGT e FA foram superiores nos animais do G1 (Tabela 2), grupo que corresponde a animais com idade menor ou igual a 12 meses, incluindo os recém-nascidos. Mesmo não sendo possível a confirmação desta hipótese, supõemse que o valor médio da ureia nos animais do G1 poderia estar relacionado a um maior aporte proteico por meio da ingestão do colostro ou leite oriundos de fêmeas ovinas suplementadas durante a gestação, em virtude das características de manejo nutricional adotado na propriedade, identificados durante a colheita das amostras, além da boa condição corporal da ovelhas. Apesar de haver diferença no valor de ureia para o G1, este não diferiu daqueles relatados na literatura (SANTANA et al., 2009). A atividade da enzima GGT é alta no colostro e sua atividade no soro de bezerros que ingeriram colostro é 60 a 160 vezes maior do que em animais adultos (FAGLIARI et al., 1996; RADOSTITS et al., 2007). O valor da FA pode estar relacionado à intensa atividade osteoclástica nos animais jovens (THRALL, 2006). Apesar da diferença encontrada entre as faixas etárias, os valores de uréia, GGT e FA foram semelhantes aos obtidos por Santana et al. (2009). Verificou-se ainda diferença entre os valores de albumina e globulinas de acordo com a faixa etária, valores estes inferiores aos obtidos por Batista et al. (2009).
Comparando-se os animais de acordo com o sexo, observou-se que a quantidade de leucócitos totais foi maior nos machos, assim como o número de neutrófilos segmentados, neutrófilos bastonetes e linfócitos (Tabela 1). Para a avaliação dos parâmetros de acordo com o sexo, os animais foram agrupados apenas em machos e fêmeas, não se fazendo distinção das idades.

Com relação aos valores bioquímicos, os valores de creatinina, proteínas totais séricas e globulinas foram superiores nas fêmeas (Tabela 2). Considerando os aspectos produtivo e reprodutivo, as fêmeas necessitam de um aporte alimentar protéico maior do que os machos, para que possam ganhar peso, adquirirem maturidade reprodutiva e produzirem colostro e leite em quantidade e qualidade adequados, o que poderia justificar os valores superiores de creatinina e proteínas totais séricas nas fêmeas. Meira Junior et al. (2009) não encontraram diferenças significativas entre os machos e fêmeas, para os valores de proteínas totais, em ovinos da raça Santa Inês.

Os valores de PT, albumina e globulinas foram semelhantes aos obtidos por Ramos et al. (1994) e Batista et al. (2009) e os valores de FA, GGT e AST foram semelhantes aos de Santana et al. (2009). Os valores de uréia e creatinina foram semelhantes aos obtidos por Ramos et al. (1994) e por Santana et al. (2009), e diferiram dos valores obtidos por Batista et al. (2009). Neste último trabalho, os animais avaliados eram criados na região Nordeste, que apresenta características climáticas bem definidas em estação seca e chuvosa, comprometendo na maioria das vezes a qualidade da dieta e promovendo diferença entre os resultados encontrados nestes trabalhos.

Com base nos resultados encontrados foi possível determinar os valores de referência para ovinos da raça Dorper, além de identificar a influência dos fatores etários e sexuais nos parâmetros bioquímicos e hematológicos destes animais. Essas variações fisiológicas são importantes para a interpretação 
dos achados laboratoriais em conjunto com o exame físico do paciente, para o estabelecimento do diagnóstico e prognóstico das principais enfermidades que acometem animais desta espécie.

\section{Referências}

BATISTA, M. C. S.; CASTRO, R. S.; REGO, E. R.; CARVAlHO, F. A. A.; SILVA, S. M. M. S.; CARVALHO, C. C. D.; RIET-CORREA, F. Hemograma, proteinograma, ionograma e dosagens bioquímicas e enzimáticas de ovinos acometidos por conidiobolomicose no Nordeste do Brasil. Pesquisa Veterinária Brasileira, Rio de Janeiro, v. 29, n. 1, p. 17-24, 2009.

BENESI, F. J. Hematologia de bezerros recém-nascidos. Influência da asfixia neonatal, do tipo do parto e da ingestão de colostro sobre a crase sanguínea. 1992. Tese (Livre Docência em Clínica e Cirurgia Animal) - Faculdade de Medicina Veterinária e Zootecnia. Universidade de São Paulo, São Paulo.

BIRGEL, E. H. Hematologia clínica veterinária. In: BIRGEL, E. H.; LARSSON, M. H. M. A.; HAGIWARA, M. K.; VASCONCELOS, S. A.; LARSSON, C. E.; BENESI, F. J. Patologia clínica veterinária. São Paulo: Sociedade Paulista de Medicina Veterinária, 1982, p. 2-49.

CARVAlHO, E. B.; OliveIRA, M. A. G.; DOMINGUES, P. F. Base para criação de ovinos no Estado de São Paulo, São Manoel: ASPACO, 2001. 93 p.

DIRKSEN, G.; GRÜNDER, H. D.; STÖBER, M. Exame clínico dos bovinos. 3. ed. Rio de Janeiro: Guanabara Koogan, 1993. 419 p.

FAGLIARI, J. J.; OLIVEIRA, E. C.; PEGORER, M. F.; FERRANTE JUNIOR, L. C.; CAMPOS FILHO, E. Relação entre o nível sérico de gamaglobulinas e as atividades de gamaglutamiltransferase, fosfatase alcalina e aspartato aminotransferase de bezerros recémnascidos. Arquivos Brasileiros de Medicina Veterinária e Zootecnia, Belo Horizonte, v. 48, n. 2, p. 105-112, 1996.
HOFFMANN, W. E.; SOLTER, P. F. Diagnostic enzymology of domestic animals. In: KANEKO, J. J.; HARVEY, J. W.; BRUSS, M. L. Clinical biochemistry of domestic animals. 6. ed. New York: Academic Press, 1997. p. 351-378.

MEIRA JUNIOR, E. B. S.; RIZZO, H.; BENESI, F. J.; GREGORY, L. Influência dos fatores sexuais e etários sobre a proteína total, fração albumina e atividade sérica de aspartato-aminotransferase e gama-glutamiltranferase de ovinos da raça Santa Inês. Brazilian Journal Veterinary Research and Animal Science, São Paulo, v. 46, n. 6, p. 448-454, 2009.

RADOSTITS, O. M.; GAY, G. C.; BLOOD, D. C.; HINCHCLIFF, K. W. Clínica veterinária: um tratado de doenças dos bovinos, ovinos, suínos, caprinos e equinos. 9. ed. Rio de Janeiro: Guanabara Koogan, 2007. 1737 p.

RAMOS, J. J.; VERDE, M. T.; MARCA, M. C.; FERNANDÉZ, A. Clinical chemical values and variations in Rasa Aragonesa ewes and lambs. Small Ruminant Research, Oxford, v. 13, n. 2, p. 133-139, 1994.

ROSENFELD, G. Corante pancrômico para hematologia e citologia clínica. Nova combinação dos componentes de May-Grunwald e do Giemsa num só corante de emprego rápido. Memórias do Instituto Butantan, v. 20, p. 329-335, 1947.

SAMPAIO, I. B. M.Estatística aplicada à experimentação animal. Belo Horizonte: UFMG, 1998. 221 p.

SANTANA, M. A.; SILVA, D. G.; BERNARDES, P. A.; PIZAURO, L. J. L.; MALUTA, R. P.; AQUINO, G. V.; GARCIA, K. O.; ÁVILA, F. A.; FAGLIARI, J. J. Hemograma e perfil bioquímico sérico de ovinos em idade de abate. In: CONGRESSO BASILEIRO DE BUIATRIA, 8., 2009, Curitiba. Anais... Goiânia: Ciência Animal Brasileira, 2009. p. 286-289. Suplemento 1.

SCHALM, O. W. Veterinary hematology. Philadelphia: Lea and Febiger, 1961. 386 p.

SOUSA, W. H.; LEITE, P. R. M. Ovinos de corte: a raça Dorper. João Pessoa: EMEPA, 2000. 75 p.

THRALL, M. A. Hematologia e bioquímica clínica veterinária. São Paulo: Roca, 2006. 592 p. 